\title{
Consumers' Acceptance towards Green Technology in Automotive Industries in Malacca, Malaysia
}

\author{
Nusaibah Mansor ${ }^{1}$, Siti Norbaya Yahaya ${ }^{1}$, Nurul Zarirah Nizam ${ }^{2} \&$ Yasuo Hoshino ${ }^{2,3}$ \\ ${ }^{1}$ Graduate School of Business Administration and Computer Science, Aichi Institute of Technology, Nagoya, Japan \\ ${ }^{2}$ Graduate School of Business Administration, Aichi University, Nagoya, Japan \\ ${ }^{3}$ Institute of Policy and Planning Sciences, University of Tsukuba, Tsukuba, Japan \\ Correspondence: Nurul Zarirah Nizam, Graduate School of Business Administration, Aichi University, Nagoya, \\ Japan. E-mail: zarirah@utem.edu.my
}

Received: October 18, 2013

Accepted: November 14, $2013 \quad$ Online Published: January 11, 2014

doi:10.5430/ijba.v5n1p27

URL: http://dx.doi.org/10.5430/ijba.v5n1p27

\begin{abstract}
The environmental global issues reposition industries to produce more environmental friendly product that will reduce damages towards global environment leading to adoption of green technology including automotive industries. However, Malaysian consumers' readiness to accept green technology embedded in vehicle need researching. Based on cost and benefit analysis, this research aims at revealing buying decision on vehicle adopting green technology testing on sample of regression is used. The study reveals that Malaysian consumers acceptance of environmental friendly products are still low, hence, this study provides future insight to the industries on consumer level of intention to purchase green technology based vehicle and how to move further in the technology is recommended.
\end{abstract}

Keywords: green technology, automotive, environment, consumer behavior

\section{Introduction}

Environmental problems are now becoming global issue. One of the major industries contributed to environmental problems is automotive industries. Harmful gases released polluted the quality of air and wastes in material production of automobiles contribute a lot towards damaging the environment. Fuel consumption leads to greenhouse gases emission and causing climate changes. This issue is becoming more serious urging global community to take drastic actions before facing great threat to the human survival. If effective measures are not taken early to prevent such effect, sooner or later it will cause irreversible loss and offset to the economic development of a country, even worst it can also cause social instability.

Considering this issue, many manufacturing companies find that by producing environment friendly products will give them chance to make a profit. Added to it consumers start to seek for other options for mode of transportation when the fuel price skyrocket. Sales of vehicles which consume more fuel begin to slip. Production volume are becoming lower, making it more unprofitable. Pressure on environmental issues from the society and tough regulations enforce by the government, makes automaker to produce more cost effective vehicles and appeal to their customers. However due to high cost of making this type of vehicle companies need to reconsider it because it becomes disadvantages for them. Not only they might have problems with competitor's imitation but also consumer demands.

Because people's standard of living starts to improve, the number of private cars increases and contribute more to damage the environment. Automakers start to innovate to make sure not only they get hold of market share back but also revive themselves from becoming the leading contributor polluting the environment. People are expected vehicles of the future not only fuel efficient but also run cleaner. Major automakers are competing into making environmental friendly vehicles. Hybrid cars are currently placing their position steadily among traditional vehicles. Sales of this vehicle type are seeing stable increase in the recent years, showing people are becoming more environmental conscious. Engine runs efficiently as well as reduces gas emission into the environment.

On the Malaysia perspective, other than facing challenges on environmental issues, automotive industry also face intensifying business environment. Furthermore, with the realization of Asian Free Trade Area (AFTA) in 2005, Malaysian automakers begin to experience the impact. Due to issues and challenges faced by automotive industry, 
the situation has force the industries to penetrate niche market using new technology approach; green technology. Malaysia started to accelerate its economic development as developing country after independence. The people standard of living starts to improve making more people to use private cars. The increase number of automobile means increasing damages to the environment. Under the pressure of government and environmental NGOs, automotive industry tries to seek new opportunity by adopting green technology.

However, the issue remains is whether Malaysian consumers are ready to embrace green technology in making buying decision. The fact that Malaysian consumers acceptance of environmental friendly products are still low, hence this study will provide future insight to the industries on consumer level of acceptance on green technology of automobile as desired by consumer.

\subsection{Consumer Perspective on Green Buying}

Several studies on consumer intention to purchase green products found several reasons for their behavior. Result from a research by Wang Ying (2010) points that innovation feature, consumer variables, supporting facilities and services closely related to consumer intention to purchase green car. These three variables, consumer factors contributed as the most important factors compare to the other two variables. From the consumer perspective, it is import for them to have the sense of honour when they own a green car. They also take into account on the income when to consider purchasing green products. The government also should intervene by providing supports to consumers which may as well boost sales for green cars. On the innovation features the research suggested automakers should consider increase investment in vehicle operability, for example safety and performance to satisfy consumer basic needs. Mainieri et al. (1997) approach consumer buying attitude on products that are environmentally beneficial in their research. Findings of this research resulted consumer attitude related closely with their concern towards the environment.

\section{Hypothesis Development}

Consumers' point of view should be taken into consideration in order to create niche market for green product in automotive industries. Several previous studies have included consumers' preferences on green product. Thurston et al. (2000) develop a framework to identify consumers' preferences in buying green products. Cost, quality and environmental factors were proposed in a model as the main preference before consumers decide to buy green product. Meanwhile, study by Hasrini and Firmanzah (2009) on determining factors that influence consumers' decision to buy green product in Indonesia conclude that consumers' intention to buy green design products depends on their perception on environmental benefits, attainable cost and comparative cost. A research in China, consumer decision to purchase green cars based on several aspects, which include car brand, functional factors, economic income, car design, and sense of honour and among others. It is conducted on macro level involving economic and also social impact (Wang Ying, 2010). This study proposed hypothesized variables relationship as follows based on several proposed variables several literatures:

Hypothesis 1: Environmental benefit has direct effect on consumer intention to buy green technology automobile.

Hypothesis 2: Self-to-benefit has direct effect on consumer intention to buy green technology automobile.

Hypothesis 3: Comparative cost has direct effect on consumer intention to buy green technology automobile.

Hypothesis 4: Attainable cost has direct effect on consumer intention to buy green technology automobile.

\section{Methodology}

In order to obtain reliable information from the respondents, established and validated scales were selected for data collection. In this study, the survey instrument of intention to buy green technology automobile on the independent variables were adopted from the scales developed by Hasrini and Firmanzah (2009). The questionnaires has been divided into four several characteristics of buying product (environment benefit, benefit to self, comparative cost and attainable cost) by private automobiles owners which focusing in Malacca. Based on randomly approach and surveying distribution, only 200 respondents which are selected. Plus, since this study is a short term grant which refer to very limited time and cost. The respondents were asked to rate each item on a 5-point Likert scale from $1=$ strongly disagree to $5=$ strongly agree. 


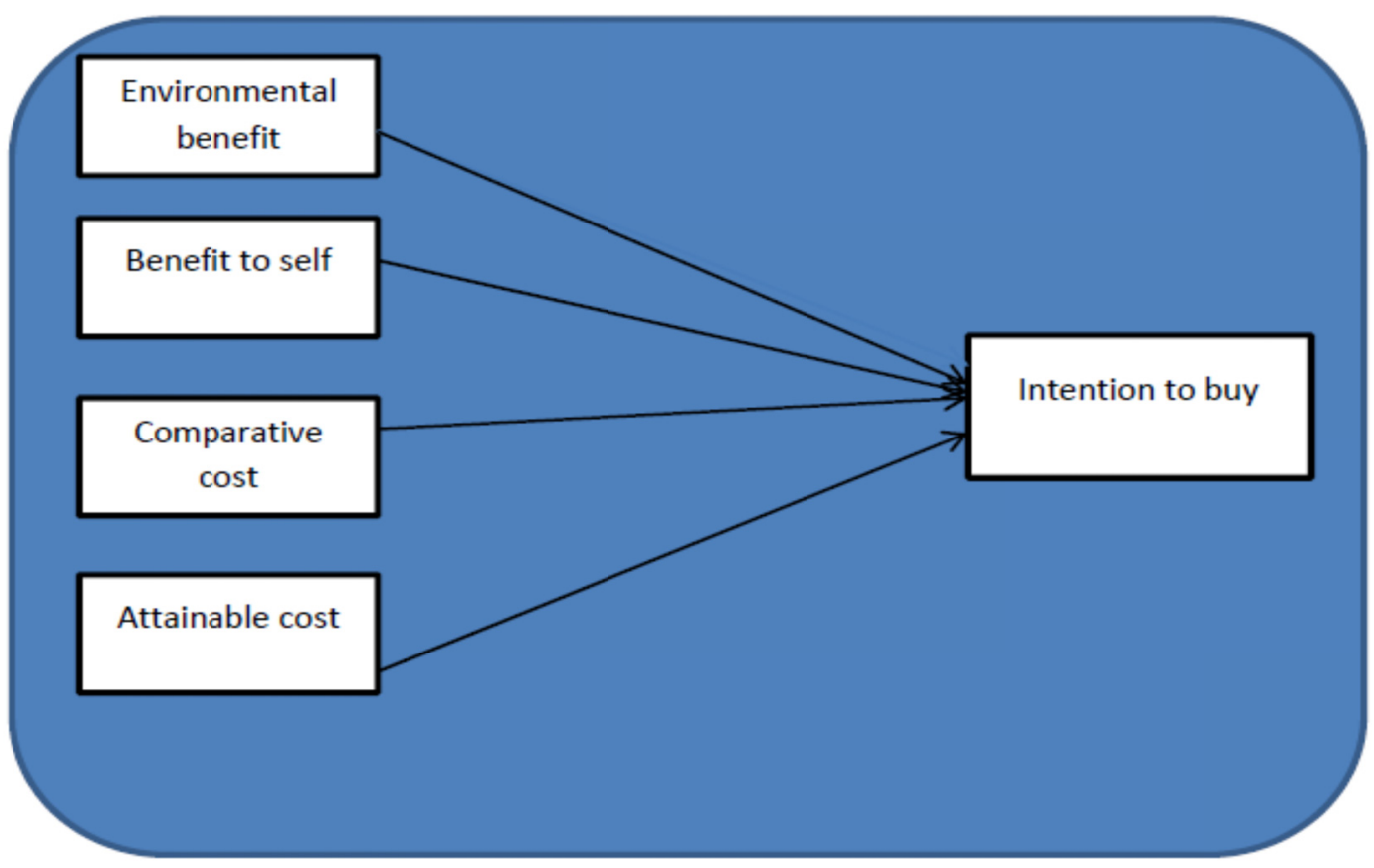

Figure 1. Framework

\section{Data Collection and Analysis}

The questionnaires for this study administered 200 private automobile owners from around Malacca, Malaysia. The owners represent automotive user and have been a growing population in Malaysia. The respondents completed the survey and were assured anonymity. Participants of this survey consisted of both sexes and of different races. About 196 completed questionnaires were obtained and sufficiently complete to be usable. The majority of the respondents were male (57\%) and of Malay ethnicity (79\%). Female respondents represent by another $43 \%$ of all respondents. Other ethnics, Chinese stands for $9 \%$ and Indians for $6 \%$ only. Of the 196 respondents, $62 \%$ of them were between age 20 and $30,12 \%$ were between age 31 to $40,5 \%$ were between age 41 to $50,2 \%$ were between age 41 to 50 and $17 \%$ were younger than age 20 .

In terms of their education level, $38 \%$ of the respondents graduated with degree. About $41 \%$ attended secondary school and finished their SPM/MCE level. Most of the respondents have income between RM1, 001 to RM3, 000 of $57 \%$. Only small number of respondents from high income group which represent $2 \%$.

In order to test each hypothesis, correlation analysis is used against dependent variable on four independent variables. Regression test is employed in this study to test the significant of all independent variables on the consumer intention to purchase green technology vehicle.

Table 1. Statistical result

\begin{tabular}{lll}
\hline Hypothesis & rp & Results \\
\hline H1: Environmental benefit $\rightarrow$ Intention to buy & $0.695^{*}$ & Accepted \\
\hline H2: Benefit-to-self $\rightarrow$ Intention to buy & $0.531^{*}$ & Accepted \\
\hline H3: Comparative Cost $\rightarrow$ Intention to buy & $0.584^{*}$ & Accepted \\
\hline H4: Attainable Cost $\rightarrow$ Intention to buy & $0.395^{*}$ & Accepted
\end{tabular}

* Significant at 0.01 level 


\section{Result and Discussion}

From the statistical result, it can be concluded that environmental benefits of green vehicles positively influence customers' intention to buy. The result indicates strong relationship between these two variables. As a result, hypothesis 1 is accepted. Benefit to self does also significantly influence customers' intention to buy green vehicle, therefore Hypothesis 2 is also accepted. While comparative cost and attainable cost significantly influence customers' intention to buy green products, Hypotheses 3 and 4 are accepted. Regression analysis indicates all four independent variables are significant towards the intention of consumer to purchase green technology vehicle with $87 \%$ independent variables effect towards dependent variable. In all the Pearson Correlation test resulted significant relationship of each independent variables with consumer intention to buy green technology vehicle at 0.01 levels. However attainable cost indicates a weaker relationship. Whereas environmental benefits positively influence consumer intention to purchase green car with the strongest relationship $(\mathrm{rp}=0.695)$.

Consumers' attitude towards becoming more environmental friendly reflected in their preference of choice when it comes to their intention to purchase green technology automobile (Mainieri et al., 1997). It is noteworthy then to conclude in this study environmental benefits towards the consumers highly supported their intention. The other variables not to be ignored; benefit-to-self, comparative cost and attainable cost significantly affect consumer intention to purchase green technology vehicle even though the relationships not too strong.

\section{Conclusion}

This paper studies the customers' perception of the value of green technology in automobile based on the intangible benefits and cost. These two factors are selected in order to address the main weaknesses of green products as described earlier. From this study, it is revealed that customers' intention to buy green car in Malaysia depends on their perception on environmental benefits, benefit-to-self, attainable cost and comparative cost. Therefore, the main market target of green cars in Malaysia is customers with higher degree of environmental concern. Automakers must ensure that environmental benefits are actually achieved at the final products stage.

Otherwise, customers will not trust the products offered. If this happens, it is likely that the products will not be successful in the market. Another consideration must be addressed by automakers not only on environmental benefits to the consumer but also price. Consumer may will to spend a lot green technology vehicle because of its benefit, but when automakers put a high price on it, it may change their decision to purchase.

\section{References}

Chen, Hao, \& Guo, Yuqin. (2000). Green Methodologies and Technologies of Switched Reluctance Motor Drive. Proceedings of 3rd World Congress on Intelligent Control and Automation, Hefei, China.

Hasrini, Sari, \& Firmanzah. (2009). Green Product Design: Identifying Determinant Factors That Influence Customers' Decision to Buy. Proceedings of the $10^{\text {th }}$ APIEMS Conference. Kitakyushu, Japan.

Heng, Xiaoqing, \& Zou, Chengxiao. (2010). How Can Green Technology Be Possible. Asian Social Science, 6(5), 110-114.

Mainieri, T., Barnett, E.G., Valdero, T. R., Unipan, J.B., \& Oskamp, S. (1997). Green Buying: The Influence of Environmental Concern on Consumer Behavior. Journal of Social Psychology, 137(2), 189-204. http://dx.doi.org/10.1080/00224549709595430

Thurston, D.L., Alvarado, J., Mangun, D., \& Hoffman III, W.F. (2000). Cost, quality, and environmental tradeoffs of printed circuit board assembly. The Engineering Economist, 45(3), 206-231. http://dx.doi.org/10.1080/00137910008967550

Wang, Ying. (2010). Chinese Consumer's Decision-making in Purchasing Green Cars. IEEE, 978-1-4244-5326-9/10. 